Botanical Research at Peradeniya.

In The Times of Ceylon, April I2, is published a communication, dated June 20 , I910, from the Governor of Ceylon to the Secretary of State for the Colonies on the question of a Department of Agriculture for that colony. With the proposals put forward in that memorandum we are not concerned, but there is one feature in connection with it against which we cannot but strongly protest. Appended to the memorandum are certain notes by $\mathrm{Mr}$. Dunstan, of the Imperial Institute, of which one runs as follows :-

"Owing to the agricultural duties which are now performed by the botanical officers at Peradeniya, and for which they are not specially qualified, no botanical research is being carried on, and the scientific reputation of the establishment, which was at a high level in the days of Thwaites and Trimen, is suffering."

We are confident that this statement cannot be justified. A reference to the Annals: of the Royal Botanic Gardens, Peradeniya, founded by Dr. Willis in I9OI, gives evidence of the amount of valuable work that has been carried out in recent years. We may mention, without attempting to be exhaustive, the researches of Messrs. Green, Holtermann, Keeble, Lang, Lock, Parkin, Pearson, Petch, Smith, Svedelius, Willis and Wright, which have all been carried out at Peradeniya during Dr. Willis's directorship. At the present time Dr. Willis and Dr. Lock, and Messrs. Petch and Green, are actively engaged in research.

In our opinion there would be a general agreement among biologists that the high reputation of the Royal Botanic Gardens has been fully maintained-to say the least of it-under the direction of Dr. Willis. To the sympathy of the staff with scientific progress, and to their ability in smoothing the way for those who visit the gardens for purposes of research, two of us, who lately stayed there for scientific work, can personally testify.

We are relieved to read that the Secretary of State, in his answer to the memorandum, has not associated himself with the paragraph above quoted. But we feel bound to make some protest against what seems to us to give an entirely misleading impression of the high position, as a centre of research, which Peradeniya has attained under Dr. Willis's initiative and guidance.

R. H. Biffen, Professor of Agricultural Botany.

F. F. Blackman, Reader in Botany.

Francis Darwin.

J. Stanley Gardiner, Professor of Zoology.

R. C. Punnett, Professor of Biology.

A. C. SEward, Professor of Botany.

A. E. Shipley, Master of Christ's College and Reader in Zoology.

T. B. Wood, Drapers Professor of Agriculture.

Cambridge University, May.

\section{The Heraldic Yale.}

Supposing a traveller on his return from Africa were to tell a friend in the Heralds' Office that he had seen a beast, in general appearance like an antelope, with divided hoofs and a long tail bunched out at the end like an elephant's: having horns, roughly corrugated and protuberant on his forehead like a ram's, though he could not be quite sure as to their form, because he saw him only in profile, and they seemed movable, one sometimes pointing forward and the other backward: further, that he had two enormous tusks and a lower jaw like a goat's, that is, with a long beard.

His friend might take out his pencil and embody what he was told in a rough sketch something like this, Fig. I, saying, "That's very interesting, for your description of the beast combines all the characters of the heraldic Yale, which some say had an African origin."

Supposing the traveller then strolled round to the British Museum and reproduced, as well as he could, the sketch drawn by his heraldic friend, but, on being cross-examined, was forced to admit that what appeared to him to be tusks might have been the tips of the beast's curved horns, which from another point of view did seem to point different ways: that the upper part of his tail was not covered with short hair only, as in the elephant, but was more bunchy below, and from the animal's manner of whisking it about the bunchiness was exaggerated. Supposing, also, that he was not clear as to the points or protuberances on the top of the animal's head-whether they

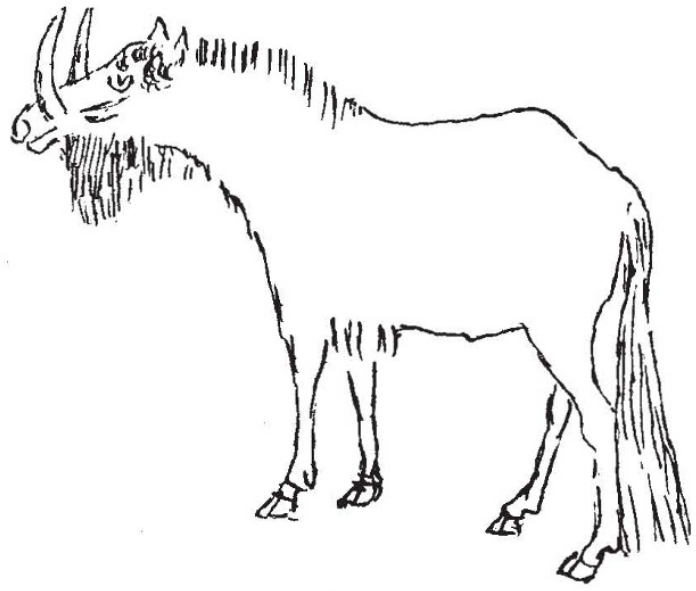

Fig. I.

were the tips of his ears or bases of horns, or both-and that he was led to modify his picture, as in Fig. 2.

His British Museum friend also might say, "That's very interesting, for it is not unlike an African beast known as the gnu, from its native name nju."

Talking the matter over afterwards with a third friend, who was learned in folk-lore, he was told that it was

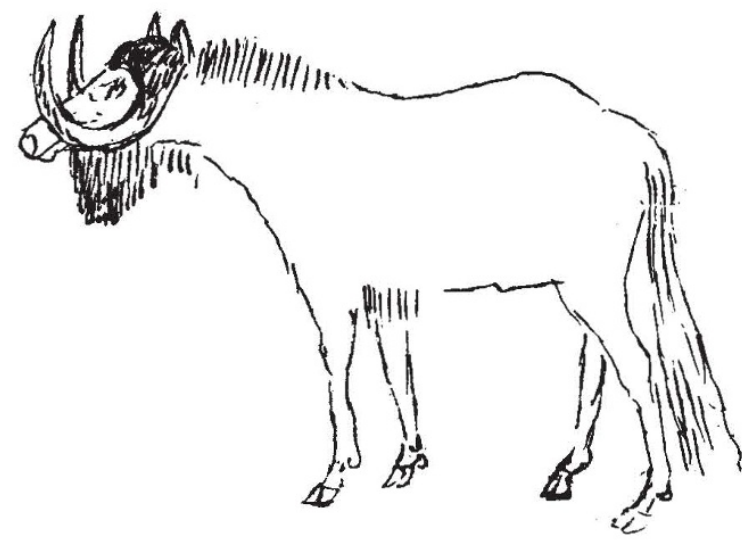

FIG. 2.

very interesting as an example of how heralds and artists had modified in time the strange form of the gnu into accord with the characters of the only animal of the kind which they did know, namely, the antelope.

T. McKenny Hughes.

\section{Dynamical Enunciations.}

UPON Newton's classic definitions and laws of motion various criticisms have been passed by A. E. H. Love, E. Mach, K. Pearson, H. Poincaré, and others.

Some writers emphasise one aspect of the subject, some another, and most are destructive rather than constructive. But, if the full value of this critical work is to reach the ordinary student, it seems desirable that teachers should have at hand some brief statements embodying those central positions on which there is fair agreement in modern thought.

As an attempt in this direction, the following enuncia tions are, with great diffidence, submitted:NO. 2169 , VOL. 86] 